\title{
Characterization of Silicone Rubber Based Soft Pneumatic Actuators
}

\author{
Yi Sun, Yun Seong Song and Jamie Paik, Member, IEEE
}

\begin{abstract}
Conventional pneumatic actuators have been a popular choice due to their decent force/torque output. Nowadays, new generation of pneumatic actuator made out of highly compliant elastomers, which we call soft pneumatic actuators (SPA), are drawing increasing attention due to their ease of fabrication, high customizability and innately softness. However, there is no effective method presented to characterize and understand these actuators, such as to measure the force and torque output, range of motion and the speed of actuation.

In this work, we present two types of SPAs: bending and rotary actuators. In addition, we have developed two measurement setups to characterize actuators of different geometries. The measured force/torque outputs of different actuators are presented and analyzed. Step responses to certain pressure input are presented and discussed. A simple model is presented to provide physical insight to the observed behavior of the soft actuators. This work provides the basis for designing customized SPAs with application-specific requirements.
\end{abstract}

\section{INTRODUCTION}

While traditional actuators such as electric motors or internal combustion engines largely dominate the industrial and academic world, applications requiring lighter, smaller or faster actuation give rise to the demand on alternative actuation mechanism such as piezoelectric unimorph actuators [1] or shape-memory-alloy (SMA) based joints [2]. These actuators show clear advantage over others in terms of weight and/or size, despite their shortcomings such as small range of motion (piezoelectric unimorphs) or slow actuation time (SMAs).

Similarly, applications requiring highly compliant actuator may benefit from using soft pneumatic actuators (SPAs) [3-5]. As the name tells, SPAs are actuated by compressed air, but an interesting difference of SPAs from the more widely known pneumatic actuators (such as the McKibben-type actuators) is that they are made almost entirely out of soft materials such as the silicone-rubber. As a result, the SPA is inherently soft and vastly customizable, making it an interesting alternative to other actuators in certain applications. However, perhaps also because of the softness and the customizability, SPAs are not very well understood, limiting the potential use of SPAs in applications with strict functional requirements.

This paper aims to provide the basis for customizing SPAs for a given requirements, such as the force/torque output, range/trajectory of motion, and speed of actuation. The possible configurations of SPAs are infinitely many - hence in

The author(s) are/was with the Department of Mechanical Engineering (IGM), École Polytechnique Fédérale de Lausanne (EPFL), CH1015, Lausanne, Switzerland.

Yi Sun : e-mail: sunyi1130@hotmail.com. Yun Seong Song : phone : +41-21-693-1083, e-mail: yun.song@epfl.ch. Jamie Paik: e-mail: jamie.paik@epfl.ch. this work we present two categories of SPAs as examples that may be useful in a range of projects. First of which is the multi-chambered bending SPA, where air pressure deforms the actuator from straight to curved. The other is the multi-chambered rotary SPA, where the deformation produces angular displacement (Fig. 1). Focusing mainly on these two types of SPAs, we present their characteristics such as the force/torque output versus the displacement given specific conditions, acquired by two customized measurement setups built exclusively for bending and rotary SPAs. In addition, we show the step-response in displacement to discuss the speed of actuation. Finally, we present a simple 2D model to provide physical insights to the data for future designs of application-specific SPAs.

\section{FABRICATION OF THE ACTUATORS}

We present two geometries of soft pneumatic actuators (Fig. 1), designed to produce the change in the curvature (bending SPA) or angular displacement (rotary SPA). The bending SPA (Fig.2-e) is a block of silicone-rubber (Ecoflex (R) 00-30, Smooth-On Inc., tensile modulus of $69 \mathrm{kPa}$ ) with embedded air chambers that inflate given pressure. A layer of unstretchable fabric coated with silicone-rubber is applied to the bottom surface. This fabric, and thus the coated layer, allows very little planar strain. Consequently, the pressurization of air chambers produces inflation on the top surface while the strain on the bottom surface remains essentially zero. This produces a bending motion where the distance between the two ends of the actuator decreases as the curvature increases (Fig.1). This motion profile can be advantageous in applications requiring "griping" motion or bending torque.

The second type of actuator, rotary SPA (Fig. 2-k) is three

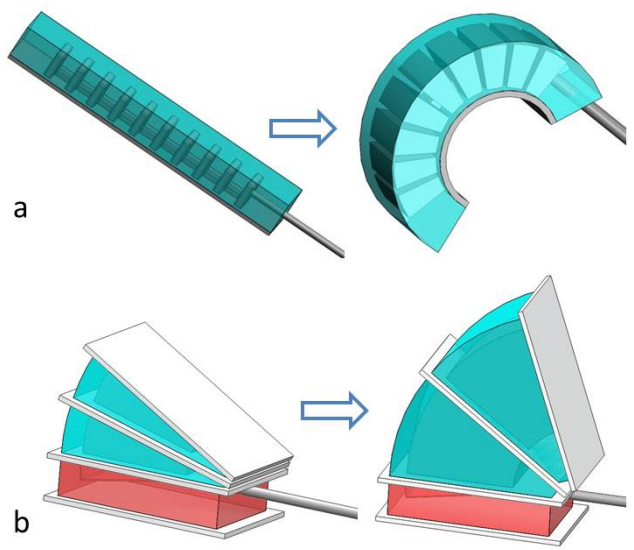

Figure 1. Illustration of the two actuator configurations. Bending SPA before and after actuation (a), and the rotary SPA before and after actuation (b). 


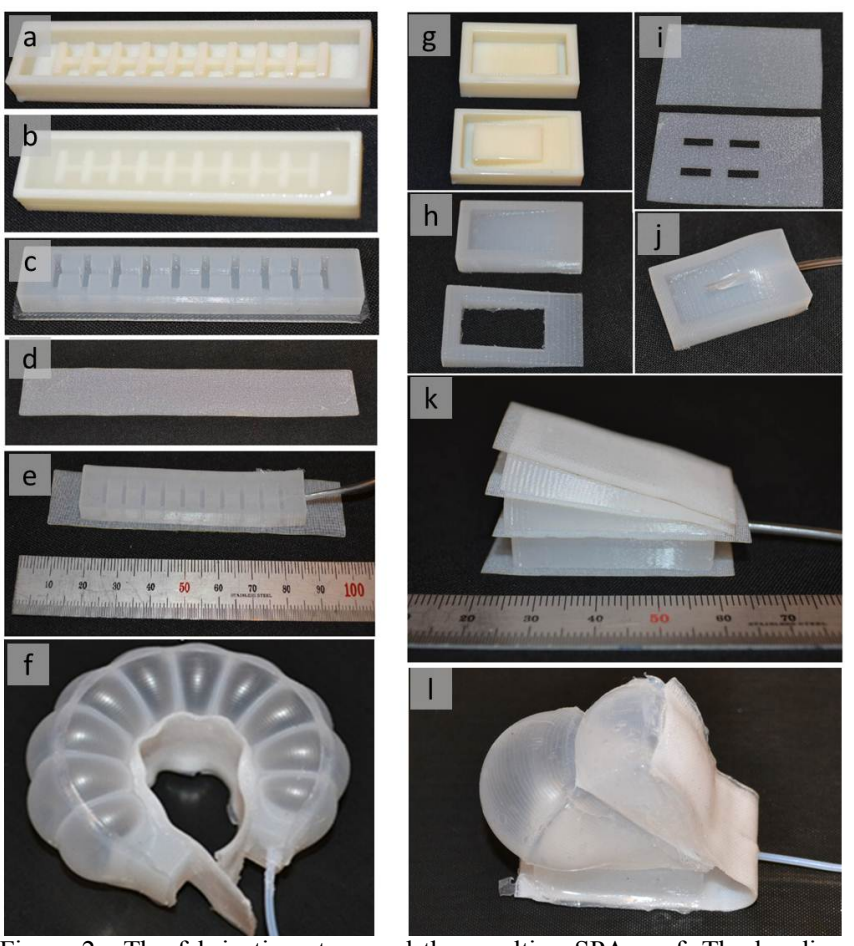

Figure 2. The fabrication steps and the resulting SPAs. a-f: The bending SPA, g-l: The rotary SPA. a: ABS plastic mold. b: Silicone-rubber is cured inside the mold. c: Resulting silicone-rubber structure. d: Strain-constraining fabric coated with silicone-rubber. e: Final outcome with an air tube. f: Bending motion given $\triangle P=25 \mathrm{kPa}$. g: ABS plastic mold for the rotary SPA. $\mathrm{h}$ : The silicone-rubber structure after molding. i: Unstretchable fabric layer before and after patterning. j: Air tube is inserted. k: The final outcome. 1 : Angular displacement given $\triangle P=25 \mathrm{kPa}$.

hallow silicone-rubber bodies with layers of aforementioned coated fabric in between. Similar to the case of bending SPA, these layers direct the structure to increase the angle between the top and the bottom layers as the actuator is pressurized. The top two silicone rubber bodies are in a pie-shape with $10^{\circ}$ internal angle (Fig. 3, right). The bottom block is a box shape to provide enough silicone-rubber volume for air tube insertion (explained below). This particular actuator can be useful in applications requiring an angular displacement of $0-90^{\circ}$.

The fabrication processes of the two SPAs are analogous to each other [3-8] (Fig. 2). Firstly, equal volume of Ecoflex ${ }^{\circledR}$ $\mathrm{A}$ and $\mathrm{B}$ solutions is mixed using centrifugal mixer (Thinky Inc., ACE-250). After degassing the mixture, it is applied into ABS plastic molds which are prepared using 3D-printing (Hewlett-Packard ${ }^{\circledR}$, Designjet 3D). The silicone-rubber is cured either at the room temperature for 4 hours or at $70^{\circ}$ for 30 minutes. Thin and compliant tube (inner diameter of $1 \mathrm{~mm}$ ) is inserted into the silicone-rubber structure [5]. The strain-constraining layer is fabricated by applying the degassed silicone-rubber solution evenly on a piece of fabric mentioned above. When cured, the coated fabric is cut to desired patterns using laser- micromachining [9]. The molded bodies are bonded together with the coated fabric using additional silicon-rubber mixture. Finally, to ensure proper insulation, flexible epoxy glue is applied near the site where

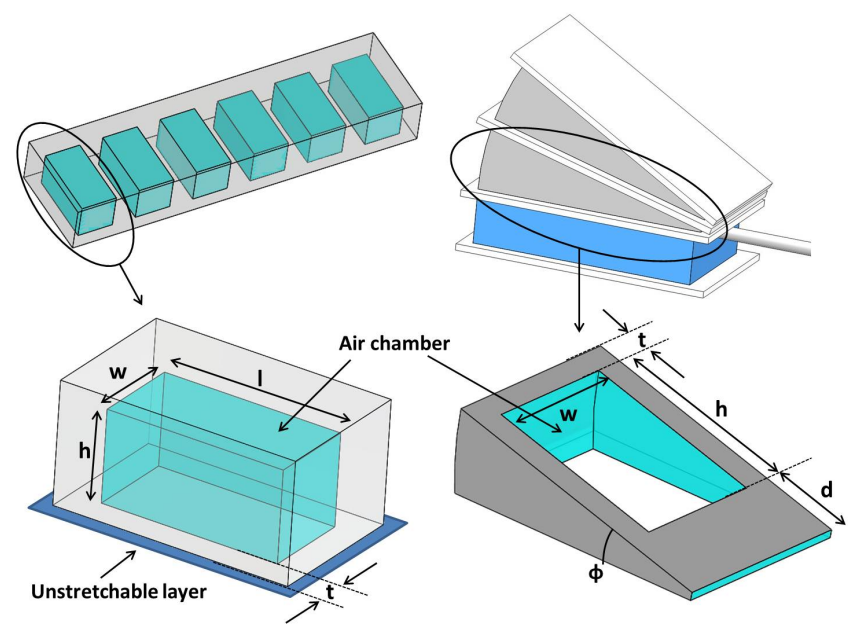

Figure 3. Schematics of the air chambers for the bending SPA (left) and the rotary SPA (right), with the surrounding silicone-rubber walls of thickness $t$. (see Table I for parameters.)

TABLE I. $\quad$ LIST OF PARAMETERS OF SPAS IN FIG. 3

\begin{tabular}{|c|c||c|c|}
\hline \multicolumn{2}{|c||}{ Bending SPA } & \multicolumn{2}{c|}{ Rotary SPA } \\
\hline Parameter & Value & Parameter & Value \\
\hline \hline$w$ & $2 \mathrm{~mm}$ & $w$ & $14 \mathrm{~mm}$ \\
\hline$h$ & $4 \mathrm{~mm}$ & $h$ & $23 \mathrm{~mm}$ \\
\hline$t$ & $2,3,4 \mathrm{~mm}$ & $t$ & $2,3,4 \mathrm{~mm}$ \\
\hline$l$ & $8 \mathrm{~mm}$ & $\theta$ & $10^{\circ}$ \\
\hline \# of chambers & 10 & $d$ & $14 \mathrm{~mm}$ \\
\hline
\end{tabular}

the tube enters the silicone-rubber structure. The fabricated bending SPAs and rotary SPAs are 8-15 $\mathrm{g}$ in weight

\section{ACTUATOR CHARACTERIZATION}

For every actuator, the characterization is more than essential to expand their application possibility. In this section, detailed characterization methods are explained.

\section{A. The Measurement Setups}

Actuator properties are a function of $\Delta P$ that enters the actuators. The thickness of the wall surrounding the air chamber affects the size of the inflated air chamber. While the wall thickness is only one of many parameters that determine the actuator characteristics, we focus in this work the effect of this single design parameter to the actuator performance for the two SPA designs since it directly affects the overall strain. Figure 3 and Table I show the current parameters of bending and rotary SPA prototypes used in this study. The thickness of the air chamber walls varies $2-4 \mathrm{~mm}$. The range of input pressure $(\Delta P)$ into these actuators is selected accordingly. For example, lower values of $\Delta P$ are applied to actuator samples with $2 \mathrm{~mm}$ wall thickness.

Figure 4 and 5 shows the measurement setups designed to characterize the bending and rotary SPAs. The linear measurement setup consists mainly of the load cell and the manually operated linear micro stage (Fig. 4). One end of the bending SPA sample is mounted on the linear micro stage (travel of $100 \mathrm{~mm}$ ), while the other end is mounted on the 


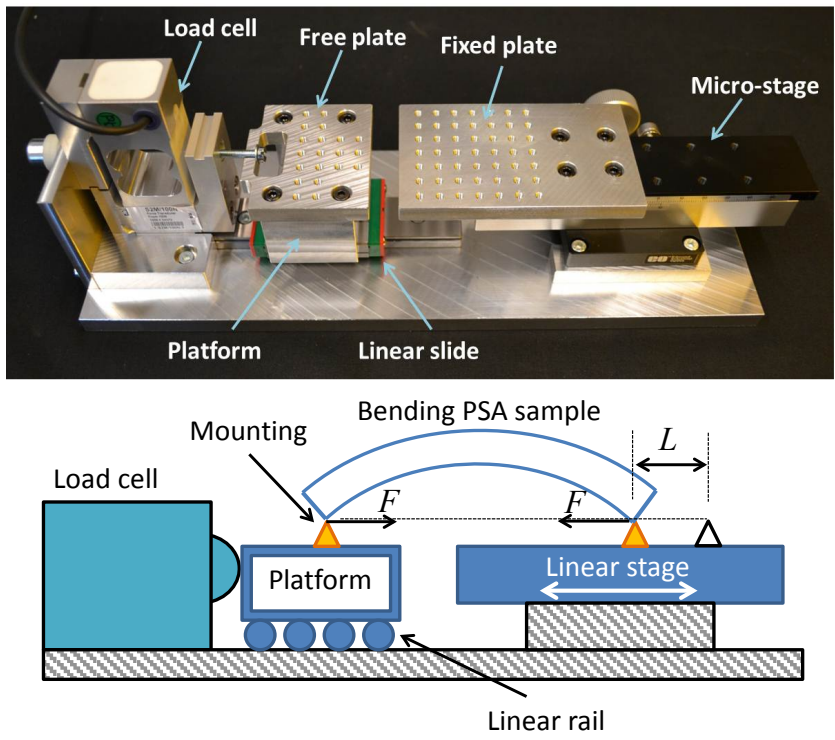

Figure 4. Photo (top) and the side view schematic (bottom) of the linear measurement setup for characterization of bending SPAs. The position of the linear stage is manually adjusted. The pulling force $(F)$ is measured as the actuator is given various input pressure at a fixed displacement.
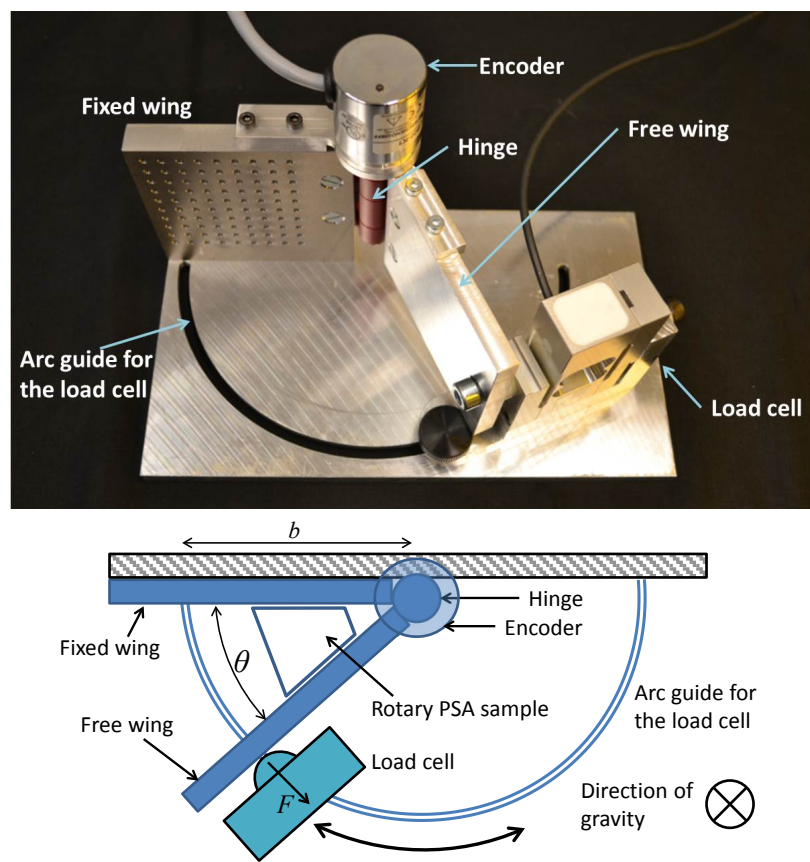

Figure 5. Photo (top) and the top view schematic (bottom) of the rotary measurement setup. The measured force $(F)$ is multiplied by the moment $\operatorname{arm}(b=100 \mathrm{~mm})$ to find the torque generated by the rotary SPA.

platform on a low-friction linear slide. The bending SPA pulls on the load cell as it is inflated, while the displacement is fixed by the non-back-drivable linear micro stage. In short, the setup measures the force as the actuator is fixed in a given displacement, pressure and wall thickness.

The rotary measurement setup consists of the load cell and the two wings sharing a rotary hinge (Fig. 5). The rotary actuator is placed in between the wings where the "free" wing can change its angular position with respect to the "fixed" wing $\left(20-160^{\circ}\right)$. Between the wings is a low-friction ball-bearing hinge which facilitates smooth folding motion of the two wings. The load cell is positioned to touch the "free" wing and then fixed in place by a screw. The precise angular position is measured by an absolute encoder. The force normal to the "free" wing is measured as the actuator is fixed in an angular position with a given pressure and wall thickness.

We also recorded in video $(120$ fps at $320 \times 240$ pixels $)$ the free movement of the actuators. The videos with visual markers are analyzed using a motion analysis program (Tracker). Post-processing of the videos provide the displacement in time given a step change in the input pressure, from which the speed of actuation is discussed.

\section{B. Force/torque-Displacement Characteristics}

As a pivotal parameter, force/torque of the two types of SPAs with respect to different displacement is measured and the results are presented.

\section{1) Bending Soft Pneumatic Actuator}

Figure 6 shows the measured mean force and the standard deviation with respect to the linear displacement, which is the change in the distance between the two ends of the actuator ( $L$ in Fig. 4). These measurements were done once for a sample at predetermined pressure and displacement. The ranges of the input pressure $\Delta P$ is lower for the samples of $2 \mathrm{~mm}$ wall thickness, as they cannot withstand as high pressure as the thicker walled samples.

Overall, as the displacement increases, the pulling force decreases in all input pressures and wall thicknesses. As can be seen in Fig. 6, the measured force at $10 \mathrm{~mm}$ displacement is always greater than the force measured at $20 \mathrm{~mm}$ displacement for any given wall thickness.

The colored data points across Fig. 6 represent data from different wall thickness samples with identical input pressure. The samples with thinner walls show greater force output with a given displacement and a given input pressure. For example, the force values from the $2 \mathrm{~mm}$ walled samples are always greater than the force values from the $3 \mathrm{~mm}$ at $30 \mathrm{kPa}$. Similarly, the force measurement of the $3 \mathrm{~mm}$ walled samples at $40 \mathrm{kPa}$ is always higher than the same measurement from the $4 \mathrm{~mm}$ samples at any given displacement.

The mean, standard deviations and the number of samples for each measurement point in Fig. 6 are given in the appendix.

\section{2) Rotary Soft Pneumatic Actuator}

Figure 6 shows the mean torque and the standard deviation with respect to the angular displacement ( $\theta$ in Fig. 5). Similar to the case of bending SPA, measurements on rotary SPA were done once per sample at certain input pressure and a prescribed angular displacement. Lower range of input pressure was applied to the thinner walled samples.

Overall, the torque exerted by the actuator at a given pressure is lower as the angular displacement is larger, regardless of the thickness of the wall. For example, for a 3 $\mathrm{mm}$ wall-thickness sample at $\Delta P=30 \mathrm{kPa}$, the block torque was nearly $1 \mathrm{Nm}$ at its original (unactuated) angular position of $20^{\circ}$, while it is reduced to nearly $400 \mathrm{Nmm}$ at $50^{\circ}$ angle. 
$2 \mathrm{~mm}$ wall thickness

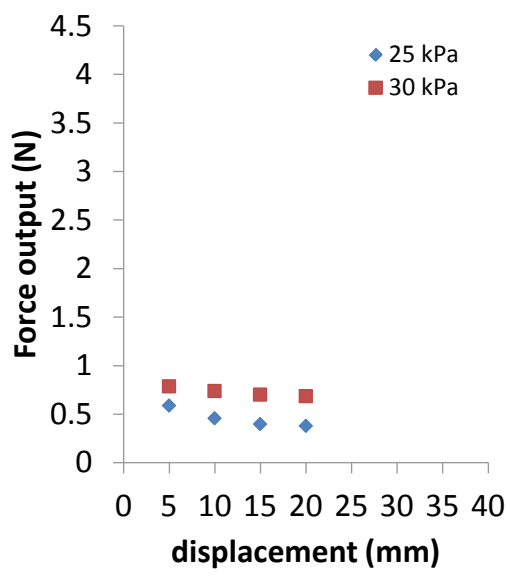

$3 \mathrm{~mm}$ wall thickness

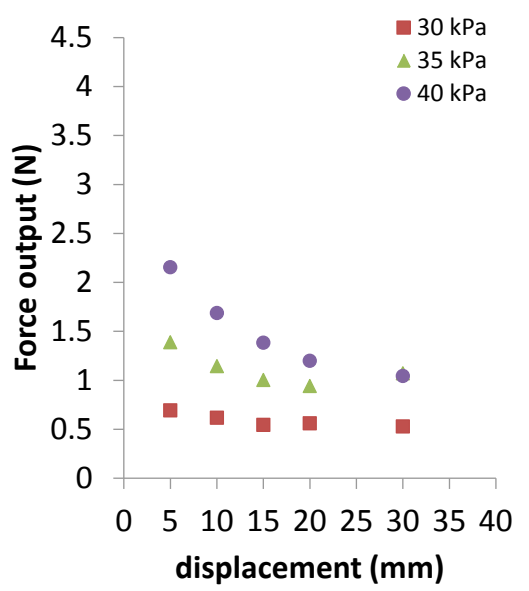

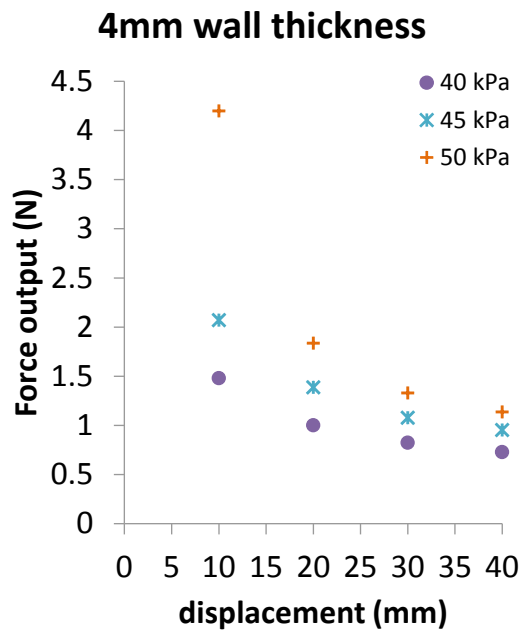

Figure 6. Force-displacement characteristics of the bending SPA samples with various wall thicknesses. The data points represent the mean measured force across a number of samples. The measured values are also given in the appendix.
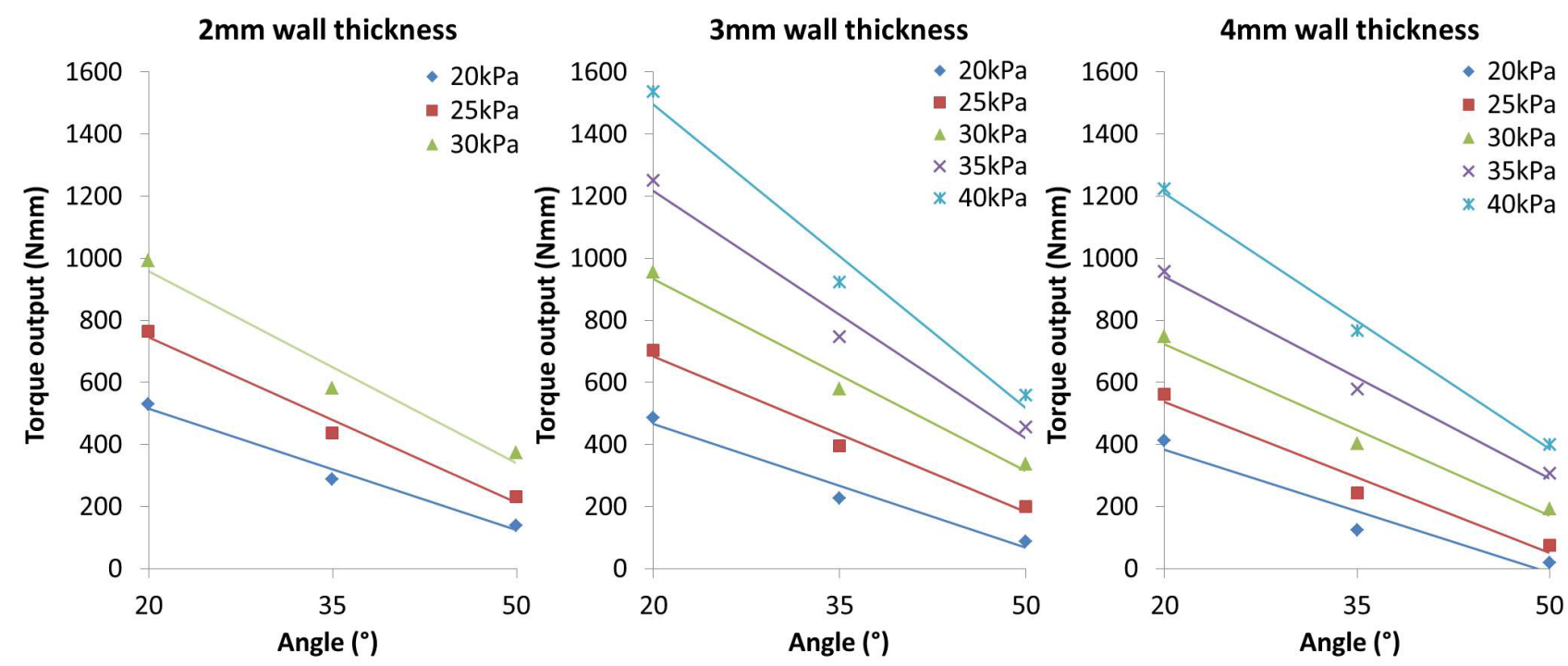

Figure 7. Torque-displacement characteristics of the rotary SPA samples with various wall thicknesses. The data points represent the mean measured torque across a number of samples. The colored lines in each graph correspond to the linear-interpolated torque output given a specific input pressure $(\Delta P) . R^{2}>0.93$ in all cases. The measured values are also given in the appendix.

The $4 \mathrm{~mm}$ wall-thickness samples showed very low torque output at $50^{\circ}$ and $\Delta P=20 \mathrm{kPa}$, since the sample almost reached its maximum displacement at the given pressure.

The samples of $2 \mathrm{~mm}$ wall thickness show higher torque output when the input pressure and the applied displacement is fixed. In Fig. 7, the lines with identical colors represent identical input pressure across the three graphs. At $\Delta P=25$ $\mathrm{kPa}$, the $2 \mathrm{~mm}$ wall thickness sample showed the block torque of nearly $800 \mathrm{Nmm}$ while the $3 \mathrm{~mm}$ and $4 \mathrm{~mm}$ samples showed roughly $700 \mathrm{Nmm}$ and $600 \mathrm{Nmm}$ block torque, respectively.

The mean, the standard deviations and the number of samples for each measurement point in Fig. 7 are given in the appendix.

\section{Speed of Actuation}

Varied applications require different speed of actuation. Here, the speeds of our actuator are given in terms of step responses.

\section{1) Bending Soft Pneumatic Actuator}

Figure 8 shows the time history of the unconstrained deformation from initially flat configuration to a ring-shape in which the two ends of the actuators meet together, given a step change in the input pressure. One sample per wall thickness was tested. As the actuators are given $\triangle P=40 \mathrm{kPa}$, it deforms from the initial zero displacement to the corresponding maximum displacement in roughly 5 to $7 \mathrm{~s}$. The samples with thicker walls have the higher maximum deformation since the sample is longer. When the actuator is depressurized, it returns to its original configuration in approximately $3 \mathrm{~s}$. The sample 

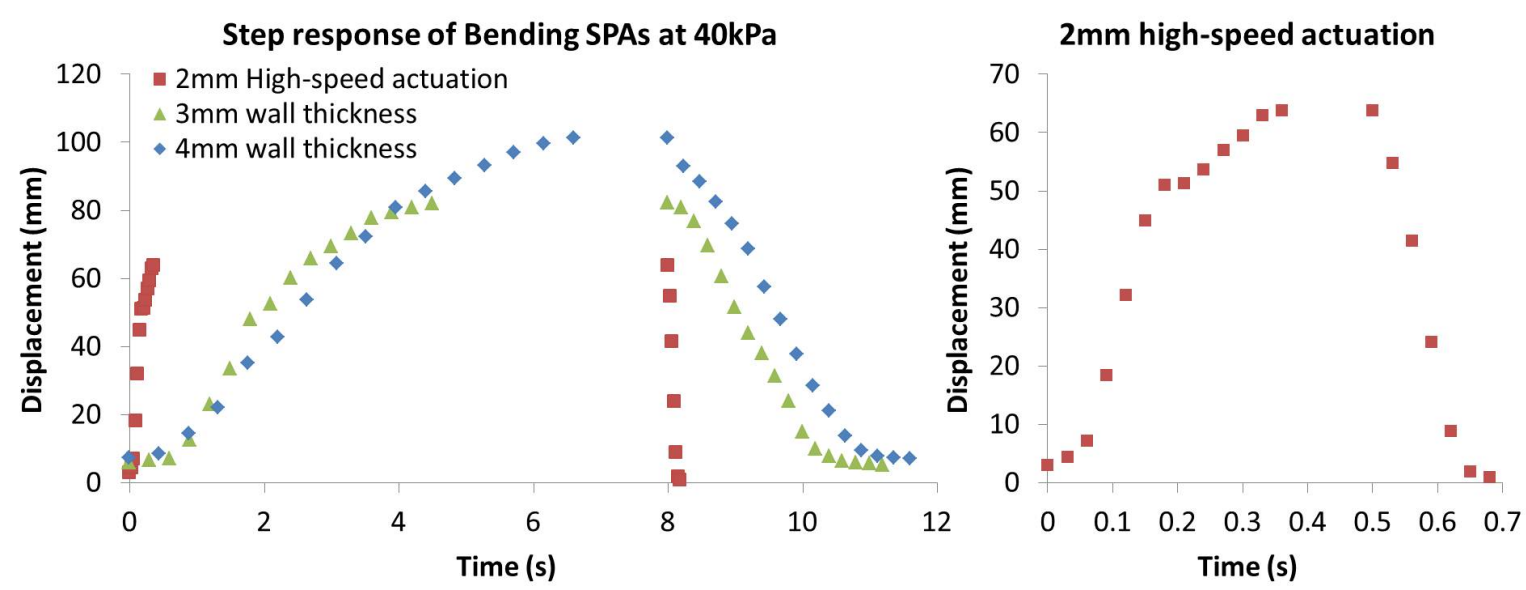

Figure 8. Linear displacement of the bending SPA samples over time when given a step change in pressure, $\triangle P=40 \mathrm{kPa}(1-8 \mathrm{~s})$ and when deactivated back to $\triangle P=0 \mathrm{kPa}(9-12 \mathrm{~s})$. The plot on the right shows in higher time-resolution activation/deactivation of the high-speed actuator. Details are presented in the text.
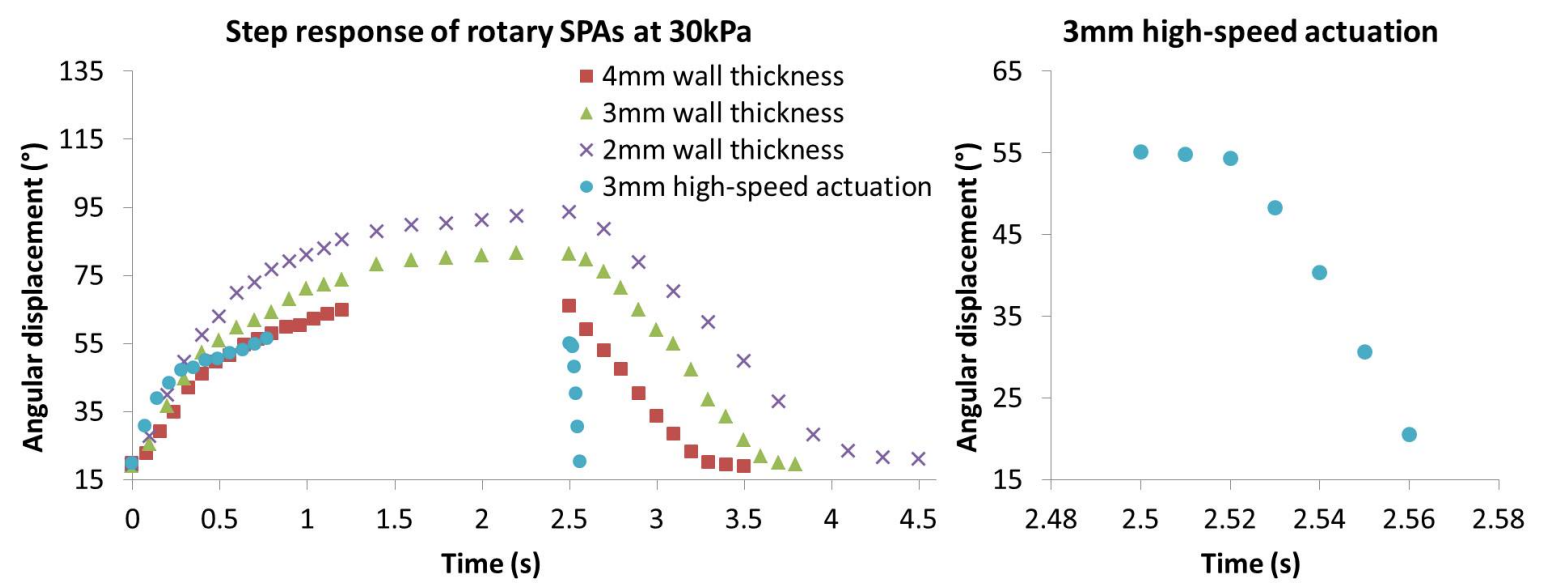

Figure 9. Angular displacement of the rotary SPA over time when activated with a step change in the input pressure, $\Delta P=30 \mathrm{kPa}(0$ to $2.5 \mathrm{~s})$ and when deactivated back to $\triangle P=0 \mathrm{kPa}(2.5$ to $4.6 \mathrm{~s})$. The plot on the right shows in higher time resolution the deactivation of the high-speed actuator. Details are presented in the text.

with thicker wall is generally slower in its response to the change in the pressure.

It is possible to increase the speed of actuation and deactivation using an exhaust tube (inner diameter of $1.6 \mathrm{~mm}$ ). Figure 8 also shows the actuation and deactivation curve for a single sample with $2 \mathrm{~mm}$ wall thickness and $500 \mathrm{kPa}$ input pressure. The tube greatly speeds up the actuation and deactivation (Fig. 8, right). The time required to reach its maximum displacement is less than $0.4 \mathrm{~s}$, and the time required to return to the actuator's original configuration is less than $0.3 \mathrm{~s}$. This is about 10 times faster than the other samples with no exhaust valves, although the wall thicknesses are not identical across the samples.

\section{2) Rotary Soft Pneumatic Actuator}

Figure 9 shows the changes in the angular displacement in time for different rotary SPA samples given a step change in the input pressure. The maximum angular displacement at $\Delta P$ $=30 \mathrm{kPa}$ is $91^{\circ}, 82^{\circ}$ and $69^{\circ}$ for the $2 \mathrm{~mm}, 3 \mathrm{~mm}$ and $4 \mathrm{~mm}$ wall thickness samples, respectively. One sample per wall thickness was tested.
Unlike bending SPA whose maximum displacement is limited by its original length, the maximum angular displacement of the rotary SPA is dependent only on the input pressure. The time history of the angular displacement resembles that of a step response of a $1^{\text {st }}$-order system, with a seemingly linear region as the actuation nears its maximum displacement. For example, the time history of angular displacement between 0.6-1.2 $\mathrm{s}$ for the $4 \mathrm{~mm}$ wall thickness samples shows an approximately straight line.

While the maximum displacement is larger for thinner walled samples, the time required to reach this displacement
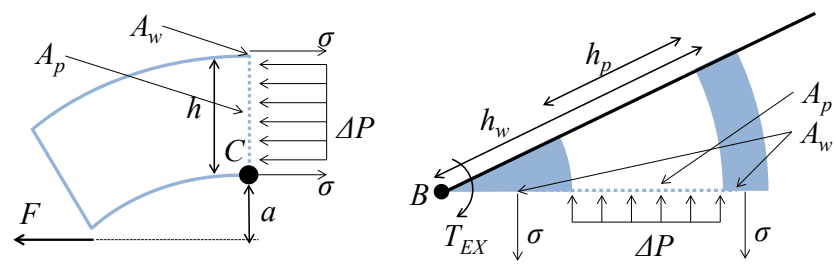

Figure 10. The forces and torques acting on the bending (left) and rotary (right) SPAs. See text for details. 
(and back to its original position) also takes longer. In other words, the thicker walled samples activate and deactivate faster, but with reduced maximum travel.

As with the bending SPA, it is possible to greatly reduce the time required for activation and deactivation by using an exhaust tube and applying much higher input pressure $(\triangle P \sim$ $400 \mathrm{kPa}$ ). Figure 9 shows that the deactivation of the sample with the exhaust tube takes less than $0.08 \mathrm{~s}$, while other samples took at least $1.0 \mathrm{~s}$ to return to its original shape.

\section{DISCUSSION}

Following the measured data, the corresponding analysis and discussion are given in this section. To verify the obtained results in the experiments, we provide simplified physical models for the two actuators, using which the experimental data can be interpreted.

\section{A. Force-Displacement Characteristics of Bending SPAs}

While a previous work discusses the change in the radius of curvature of a similar actuation mechanism [4], the force-displacement characteristics of the SPAs is not reported in the literature.

We base our actuator model on the assumption that the source of displacement for these types of actuators is the inflation of the air chamber, and the source of force is the difference in the pressure inside and outside the chamber. There is no further displacement when this force is balanced by the external force and the internal stresses of the silicone-rubber structure. That is,

$$
T_{c}=A_{P} \cdot \Delta P \cdot h / 2-A_{w} \cdot \sigma \cdot h-a \cdot F=0
$$

where $T_{c}$ is the sum of torque about the point $C$ in Fig. 10-A, $A_{p}$ is the cross-sectional area of the inflated air chamber, $A_{w}$ is the cross-sectional area of the wall, $\Delta P$ is the input pressure, $\sigma$ is the stress normal to $A_{w}$ due to the elongation of the silicone-rubber, $a$ is the moment arm, $h$ is the height of the inflated chamber, and $F$ is the external force blocking further deformation (which is measured by the load cell in Fig. 4).

As the actuator bends, it was observed that the height of the inflated air chamber does not change much, as well as the cross-sectional area of the chambers. In other words, the value of $A_{p}$ and $A_{w}$ does not change much due to the imposed displacement as long as the pressure remains the same. Hence the term $\left(A_{p} \cdot \Delta P \cdot(h / 2)-A_{w} \cdot \sigma \cdot h\right)$ in Eq. 1 can be regarded as roughly constant. On the other hand, the moment arm $a$ is increased with further displacement of the actuator. To satisfy Eq. 1, the force reading from the load cell thus decreases in response to the increased displacement, as can be seen in Fig. 6.

Thicker walled samples have larger $A_{w}$ for resisting the deformation compared to the thinner walled samples, and thus results in less inflation of the air chambers (and thus less $A_{p}$ ) given a fixed pressure. The required external force to block further deformation is thus reduced. This is illustrated by the smaller force readings from the thicker walled samples in Fig. 6 given a fixed pressure and displacement.

\section{B. Torque-Angle Characteristics of Rotary SPAs}

Similar to the case of bending SPAs, the external blocking torque can be related to the input pressure and the actuator geometry as follows.

$T_{B}=A_{P} \cdot \Delta P \cdot\left(h_{w}-h_{p} / 2\right)-A_{w} \cdot \sigma \cdot h_{w}-T_{E X}=0$

where $T_{B}$ is the sum of torque about the point B in Fig. 10-B, $h_{\mathrm{w}}$ is the distance from $\mathrm{B}$ to the centroid of $A_{\mathrm{w}}, h_{\mathrm{p}}$ is the air chamber height, and $T_{E X}$ is external torque blocking further deformation of the actuator (which is measured by the load cell in Fig. 5). This simple model assumes that the cross sectional areas, $A_{p}$ and $A_{w}$, change little due to angular displacement of the actuator, since radial expansion of the air chambers is restricted by the unstretchable coated fabric layers. Thus for a given pressure, $T_{E X}$ is in inverse-linear relationship with the stress $\sigma$ and thus the strain $\varepsilon$. This trend can be found across all plots in Fig. 7.

As with the case of bending SPAs, the thicker the wall, the smaller $T_{E X}$ is required to be. This is illustrated by the smaller torque measurement for thicker walled samples in Fig. 7.

\section{Speed of Actuation and Deactivation}

While the speed of actuation largely depends on the mass flow rate of air, it also depends on the internal force of the silicone-rubber structure resisting the inflation. The thicker walled samples with higher cross sectional area $\left(A_{w}\right)$ require more mass of air to expand further, slowing down the deformation compared to other samples. This is illustrated by the stiffer initial slope for the thinner-walled samples in Figs. 8 and 9. The time required to achieve a given displacement is generally longer for the thicker-walled samples.

On the other hand, having larger $A_{w}$ also means higher restoring force within the structure, increasing the mass flow rate of the air exiting the chambers when deactivated. Thus the deflation of the air chambers generally happens quicker in the thicker-walled samples. For example for the rotary SPA, the negative slope just at the beginning of deflation $(\mathrm{t}=2.5 \mathrm{~s}$ in Fig. 9) for the $4 \mathrm{~mm}$ walled sample is stiffer than the slopes of the $2 \mathrm{~mm}$ or the $3 \mathrm{~mm}$ walled samples.

The mass flow rate of air for the "high-speed actuators" is greatly increased due to the higher input pressure as well as the constant exhaustion of air. The radically increased actuation and deactivation rates of these actuators are shown in Figs. 8 and 9.

\section{CONCLUSION}

This work provides a platform process for selecting design parameters for these silicone rubber based SPAs which are suitable for applications requiring at least $1 \mathrm{~N}$ of force in centimeter-scale. Potential applications of these soft actuators are diverse. The bending movement of the bending SPA is analogous to human finger movements, and hence it may be used in manipulative tasks such as a finger for a robotic gripper or in an exoskeletal glove. It may also be constructed in a bundle to form an artificial muscle that contracts upon inflation. The rotary SPAs can be used as an active hinges for 
small robotic devices such as in the robotic origami structure [2]. The relatively low mass (around $10 \mathrm{~g}$ ) and the inherent softness of the material (tensile modulus of $69 \mathrm{kPa}$ ) may become useful in physical interaction tasks such as in [10].

Applications requiring faster actuation may benefit from the high-speed version of the SPAs presented above. While these actuators are not intensively characterized in this work, further analysis is warranted since they provide the solution for one of the drawbacks of the current SPAs - its speed of actuation/deactivation.

In summary, the measurements and analyses presented in this work may be useful for designing customized SPAs for applications with specific functional requirements in the future.

\section{APPENDIX}

TABlE A. Mean, Standard Deviations and Number of Samples FOR THE 2 MM WALL-THICKNESS BENDING SPA FORCE MEASUREMENT.

\begin{tabular}{|c|c||c|c|c|}
\hline \multicolumn{2}{|c||}{ Imposed Parameters } & \multicolumn{3}{|c|}{ Statistics } \\
\hline $\begin{array}{c}\text { Linear } \\
\text { Displacement } \\
(\mathrm{mm})\end{array}$ & $\begin{array}{c}\text { Applied } \\
\text { Pressure } \\
(\mathrm{kPa})\end{array}$ & $\begin{array}{c}\text { Average } \\
\text { Force } \\
(\mathrm{N})\end{array}$ & $\begin{array}{c}\text { Standard } \\
\text { Deviation } \\
(\mathrm{N})\end{array}$ & $\begin{array}{c}\text { Number of } \\
\text { Samples }\end{array}$ \\
\hline \multirow{2}{*}{5} & 25 & 0.59 & 0.003 & 2 \\
\cline { 2 - 5 } & 30 & 0.79 & 0.055 & 2 \\
\hline \multirow{2}{*}{10} & 25 & 0.46 & 0.040 & 2 \\
\cline { 2 - 5 } & 30 & 0.74 & 0.095 & 2 \\
\hline \multirow{2}{*}{15} & 25 & 0.40 & 0.060 & 2 \\
\cline { 2 - 5 } & 30 & 0.70 & 0.087 & 2 \\
\hline \multirow{2}{*}{20} & 25 & 0.38 & 0.079 & 2 \\
\cline { 2 - 5 } & 30 & 0.69 & 0.065 & 2 \\
\hline
\end{tabular}

TABLE B. MEAN, STANDARD DeVIations ANd Number of SAMPLES FOR THE 3 MM WALL-THICKNESS BENDING SPA FORCE MEASUREMENT.

\begin{tabular}{|c|c|c|c|c|}
\hline \multicolumn{2}{|c|}{ Imposed Parameters } & \multicolumn{3}{|c|}{ Statistics } \\
\hline $\begin{array}{c}\text { Linear } \\
\text { Displacement } \\
(\mathrm{mm})\end{array}$ & $\begin{array}{c}\text { Applied } \\
\text { Pressure } \\
(\mathrm{kPa})\end{array}$ & $\begin{array}{l}\text { Average } \\
\text { Force } \\
(N)\end{array}$ & $\begin{array}{l}\text { Standard } \\
\text { Deviation } \\
(N)\end{array}$ & $\begin{array}{c}\text { Number of } \\
\text { Samples }\end{array}$ \\
\hline \multirow{3}{*}{5} & 30 & 0.69 & 0.283 & 3 \\
\hline & 35 & 1.39 & 0.848 & 3 \\
\hline & 40 & 2.15 & 0.823 & 3 \\
\hline \multirow{3}{*}{10} & 30 & 0.62 & 0.301 & 3 \\
\hline & 35 & 1.14 & 0.777 & 3 \\
\hline & 40 & 1.69 & 0.746 & 3 \\
\hline \multirow{3}{*}{15} & 30 & 0.54 & 0.257 & 3 \\
\hline & 35 & 1.00 & 0.751 & 3 \\
\hline & 40 & 1.38 & 0.703 & 3 \\
\hline \multirow{3}{*}{20} & 30 & 0.56 & 0.331 & 2 \\
\hline & 35 & 0.94 & 0.710 & 3 \\
\hline & 40 & 1.20 & 0.690 & 3 \\
\hline \multirow{3}{*}{30} & 30 & 0.53 & 0.279 & 2 \\
\hline & 35 & 1.07 & 0.878 & 2 \\
\hline & 40 & 1.04 & 0.713 & 3 \\
\hline
\end{tabular}

TABLE C. MEAN, STANDARD DEVIATIONS AND Number OF SAMPles FOR THE 4 MM WALL-THICKNESS BENDING SPA FORCE MEASUREMENT.

\begin{tabular}{|c|c||c|c|c|}
\hline \multicolumn{2}{|c||}{ Imposed Parameters } & \multicolumn{3}{c|}{ Statistics } \\
\hline $\begin{array}{c}\text { Linear } \\
\text { Displacement } \\
(\mathrm{mm})\end{array}$ & $\begin{array}{c}\text { Applied } \\
\text { Pressure } \\
(\mathrm{kPa})\end{array}$ & $\begin{array}{c}\text { Average } \\
\text { Force } \\
(\mathrm{N})\end{array}$ & $\begin{array}{c}\text { Standard } \\
\text { Deviation } \\
(\mathrm{N})\end{array}$ & $\begin{array}{c}\text { Number of } \\
\text { Samples }\end{array}$ \\
\hline \multirow{4}{*}{10} & 40 & 1.48 & 0.392 & 4 \\
\cline { 2 - 5 } & 45 & 2.07 & 0.463 & 4 \\
\cline { 2 - 5 } & 50 & 4.20 & 1.664 & 4 \\
\hline \multirow{3}{*}{30} & 40 & 1.00 & 0.226 & 4 \\
\cline { 2 - 5 } & 45 & 1.39 & 0.390 & 4 \\
\cline { 2 - 5 } & 50 & 1.84 & 0.599 & 4 \\
\cline { 2 - 5 } & 40 & 0.82 & 0.204 & 4 \\
\cline { 2 - 5 } & 45 & 1.08 & 0.317 & 4 \\
\hline \multirow{3}{*}{40} & 50 & 1.33 & 0.534 & 4 \\
\cline { 2 - 5 } & 40 & 0.73 & 0.216 & 4 \\
\cline { 2 - 5 } & 45 & 0.95 & 0.324 & 4 \\
\hline
\end{tabular}

TABLE D. MEAN, STANDARD DEVIATIONS AND Number OF SAMPLES FOR THE 2 MM WALL-THICKNESS ROTARY SPA TORQUE MEASUREMENT.

\begin{tabular}{|c|c||c|c|c|}
\hline \multicolumn{2}{|c||}{ Imposed Parameters } & \multicolumn{3}{c|}{ Statistics } \\
\hline $\begin{array}{c}\text { Angle } \\
\text { displacement } \\
(\odot)\end{array}$ & $\begin{array}{c}\text { Applied } \\
\text { Pressure } \\
(\mathrm{kPa})\end{array}$ & $\begin{array}{c}\text { Average } \\
\text { Torque } \\
(\mathrm{Nmm})\end{array}$ & $\begin{array}{c}\text { Standard } \\
\text { Deviation } \\
(\text { Nmm })\end{array}$ & $\begin{array}{c}\text { Number of } \\
\text { Samples }\end{array}$ \\
\hline \multirow{3}{*}{20} & 20 & 529.3 & 40.7 & 5 \\
\cline { 2 - 5 } & 25 & 764.2 & 45.2 & 5 \\
\cline { 2 - 5 } & 30 & 991.7 & 53.4 & 5 \\
\hline \multirow{3}{*}{50} & 20 & 289.1 & 27.3 & 4 \\
\cline { 2 - 5 } & 25 & 437.3 & 18.1 & 4 \\
\cline { 2 - 5 } & 30 & 581.9 & 22.4 & 4 \\
\cline { 2 - 5 } & 20 & 138.9 & 36.9 & 4 \\
\cline { 2 - 5 } & 25 & 231.6 & 36.2 & 4 \\
\hline
\end{tabular}

TABLE E. MEAN, Standard DEVIATIONS AND NuMBER OF SAMPLES FOR THE 3 MM WALL-THICKNESS ROTARY SPA TORQUE MEASUREMENT.

\begin{tabular}{|c|c|c|c|c|}
\hline \multicolumn{2}{|c|}{ Imposed Parameters } & \multicolumn{3}{|c|}{ Statistics } \\
\hline $\begin{array}{c}\text { Angle } \\
\text { displacement } \\
\left({ }^{\circ}\right)\end{array}$ & $\begin{array}{c}\text { Applied } \\
\text { Pressure } \\
(\mathrm{kPa})\end{array}$ & $\begin{array}{c}\text { Average } \\
\text { Torque } \\
\text { (Nmm) }\end{array}$ & $\begin{array}{l}\text { Standard } \\
\text { Deviation } \\
\text { (Nmm) }\end{array}$ & $\begin{array}{c}\text { Number of } \\
\text { Samples }\end{array}$ \\
\hline \multirow{5}{*}{20} & 20 & 485.9 & 92.3 & 4 \\
\hline & 25 & 702.8 & 126.6 & 4 \\
\hline & 30 & 955.1 & 153.9 & 4 \\
\hline & 35 & 1251.9 & 186.6 & 4 \\
\hline & 40 & 1538.1 & 223.6 & 4 \\
\hline \multirow{5}{*}{35} & 20 & 226.6 & 69.5 & 4 \\
\hline & 25 & 395.1 & 83.1 & 4 \\
\hline & 30 & 579.9 & 95.2 & 4 \\
\hline & 35 & 746.9 & 95.5 & 4 \\
\hline & 40 & 924.2 & 101.2 & 4 \\
\hline \multirow{5}{*}{50} & 20 & 87.6 & 51.0 & 3 \\
\hline & 25 & 200.9 & 73.2 & 3 \\
\hline & 30 & 337.1 & 57.0 & 3 \\
\hline & 35 & 455.9 & 51.5 & 3 \\
\hline & 40 & 558.4 & 73.2 & 3 \\
\hline
\end{tabular}


TABLE F. MEAN, STANDARD DEVIATIONS AND NUMBER OF SAMPLES FOR THE 4 MM WALL-THICKNESS ROTARY SPA TORQUE MEASUREMENT.

\begin{tabular}{|c|c|c|c|c|}
\hline \multicolumn{2}{|c|}{ Imposed Parameters } & \multicolumn{3}{|c|}{ Statistics } \\
\hline $\begin{array}{c}\text { Angle } \\
\text { displacement } \\
\left(^{\circ}\right)\end{array}$ & $\begin{array}{c}\text { Applied } \\
\text { Pressure } \\
(\mathrm{kPa})\end{array}$ & $\begin{array}{c}\text { Average } \\
\text { Torque } \\
\text { (Nmm) }\end{array}$ & $\begin{array}{c}\text { Standard } \\
\text { Deviation } \\
(\mathrm{Nmm})\end{array}$ & $\begin{array}{c}\text { Number of } \\
\text { Samples }\end{array}$ \\
\hline \multirow{5}{*}{20} & 20 & 412.5 & 8.1 & 4 \\
\hline & 25 & 561.4 & 12.1 & 4 \\
\hline & 30 & 746.9 & 23.8 & 4 \\
\hline & 35 & 959 & 44.8 & 4 \\
\hline & 40 & 1223.9 & 42.7 & 4 \\
\hline \multirow{5}{*}{35} & 20 & 125.1 & 9.8 & 4 \\
\hline & 25 & 245 & 4.7 & 4 \\
\hline & 30 & 402.5 & 19.4 & 4 \\
\hline & 35 & 578.5 & 15.9 & 4 \\
\hline & 40 & 767.5 & 28.4 & 4 \\
\hline \multirow{5}{*}{50} & 20 & 18.2 & 12.7 & 2 \\
\hline & 25 & 75 & 20.4 & 3 \\
\hline & 30 & 193.5 & 15.3 & 3 \\
\hline & 35 & 308.8 & 14.8 & 3 \\
\hline & 40 & 401.1 & 5.0 & 2 \\
\hline
\end{tabular}

\section{ACKNOWLEDGMENT}

This work was supported by the Swiss National Centre for Competence in Research (NCCR) Robotics fund. The authors would like to thank Chansu Suh for his assistance in the data analysis.

\section{REFERENCES}

[1] Y. S. Song and M. Sitti, "Surface-tension-driven biologically inspired water strider robots: Theory and experiments," IEEE transaction on Robotics, vol. vol. 23, pp. 578 - 589, 2007.

[2] J. K. Paik and R. J. Wood, "A bidirectional shape memory alloy folding actuator," Smart Materials and Structures, vol. 21, p. 065013, 2012.

[3] F. Ilievski, A. D. Mazzeo, R. F. Shepherd, X. Chen, and G. M. Whitesides, "Soft robotics for chemists," Angew Chem Int Ed Engl, vol. 50, pp. 1890-5, Feb 182011.

[4] R. F. Shepherd, F. Ilievski, W. Choi, S. A. Morin, A. A. Stokes, A. D. Mazzeo, X. Chen, M. Wang, and G. M. Whitesides, "Multigait soft robot," Proceedings of the National Academy of Sciences, November 28 2011.

[5] R. V. Martinez, J. L. Branch, C. R. Fish, L. Jin, R. F. Shepherd, R. M. D. Nunes, Z. Suo, and G. M. Whitesides, "Robotic tentacles with three-dimensional mobility based on flexible elastomers," Advanced Materials, vol. 25, pp. 205-12, Jan 112013.

[6] R. K. Kramer, C. Majidi, and R. J. Wood, "Wearable tactile keypad with stretchable artificial skin," 2011 IEEE International Conference on Robotics and Automation, pp. 1103 - 1107, 2011.

[7] C. Majidi, R. Kramer, and R. J. Wood, "A non-differential elastomer curvature sensor for softer-than-skin electronics," Smart Materials and Structures, vol. 20, p. 105017, 2011.

[8] Y. Park, B. Chen, and R. J. Wood, "Design and fabrication of soft artificial skin using embedded microchannels and liquid conductors," IEEE Sensors Journal, vol. 12, pp. 2711 - 2718, 2012.

[9] A. Firouzeh, Y. Sun, H. C. Lee, and J. Paik, "Sensor and actuator integrated low profile robotic Origami," IEEE/RSJ International Conference on Intelligent Robots and Systems, 2013.

[10]Y. S. Song, Y. Sun, R. van den Brand, J. von Zitzewitz, G. Courtine and J. Paik, "Soft robot for gait rehabilitation of spinalized rodents," IEEE/RSJ International Conference on Intelligent Robots and Systems, 2013. 